\title{
Study on Historical Value Communicated by Yellow River Piano Concerto
}

\author{
Jinghua $\mathrm{Hu}$
}

Music College, Ningxia University, Yinchuan, 750021, China

\begin{abstract}
Keywords: Piano concerto, Background, Artistic characteristics, Communication, Historical significance
\end{abstract}

\begin{abstract}
Yellow River has important and special historical significance for Chinese music, because its unique temperament reflects "Yellow River" spirit of Chinese nation. Powerful rhythm in piano concerto expresses integrity character of Chinese people. This paper briefly generalizes historical background and artistic characteristics of Yellow River piano concerto and analyzes far-reaching historical value of the works in communication process.
\end{abstract}

\section{Introduction}

At the end of 1938, Wuhan fell into enemy hands. When the poet Guang Moran led anti-Japanese team to evacuate to Hukou, Yellow River, they saw boatmen in turbulent flow of Yellow River. Their resounding slogan infected him. After arriving at Yan'an, Guang Moran wrote this poem Yellow River when inspiration stroke. Xian Xinghai recomposed it and created Yellow River Cantata which becomes a classical chorus song. Yellow River piano concerto is recomposed according to Yellow River Cantata.

\section{Yellow River piano concerto}

\section{Historical background of Yellow River piano concerto}

Yellow River Cantata is the peak and model of Chinese modern large-scale vocal music works. Its powerful rhythm sensation and resounding emotional expression show Chinese patriotism and historical sense of crisis in that specific historical period. It is a heart-stirring chorus song. After it was sung for 3 decades, Chu Wanghua, Sheng Lihong, Shi Shucheng, Liu Zhuang and Xu Feixing made joint efforts to recompose the chorus song to a piano concerto in 1969. Based on continuing the style of original song, western classical piano concerto expression means were added. In terms of the structure, Chinese folk traditional music elements such as boatmen's slogan at the bank of the Yellow River were fused. After it was officially performed in public nationwide, the most violent shock in the music circle was triggered. This song is rated to own magnificent skills, epic structure, rich hierarchy and insurgent manifestation. It is one of most representative piano concertos in China.

It can be said that Yellow River Cantata has pioneering nature for Yellow River piano concerto. This song created at the end of 1930s has been sung everywhere under the guidance of specific period, infects people's emotion and owns wide mass base. Besides, Yellow River Cantata provides classical text foundation and rich emotional basis for creation of Yellow River piano concerto. If such classical large-scale chorus song is created to a piano concerto, the quality is incontrovertible. Moreover, vocal music expression form of Yellow River Cantata indirectly makes abstract expression form of piano concerto enriched. Large quantities of music materials come from chorus. So, people have inherent cordial feeling for it. It is more direct in terms of national fusion.

\section{Artistic characteristics of Yellow River piano concerto}

The most prominent characteristic of Yellow River piano concerto is that it can embody era development and Chinese advancement with the times. The theme of great people's war is expressed 
through expression form of western piano concerto and Chinese traditional music style. It reaches the effect of combination of Chinese and western elements. So, it can enjoy good fame at home and abroad and generate great artistic value and historical value.

Although Yellow River learns from western countries, it is different from traditional 4-movement structure in western concerto, but adopts 3-movement structure to show spirit of Chinese nation in revolutionary struggling. In the first movement of Prelude - The Song of the Yellow River Boatman, under the assistance of violin and trumpet, arpeggio makes the music push to the first climax. This section expresses rough trumpet sound and rowing sound of boatmen in violent storm and roaring waves. In the end of the first movement, it violates the normal method of "sonata" in western piano concerto, and more exciting circulation form is selected. It perfectly ends great momentum of the first movement.

From the second movement Ode to the Yellow River, multi-section musical form gradually expands. It has strong storage narration nature. This expresses Chinese strong fighting will and firm determination of evicting invaders out of homeland. In the second movement, slow rhythm of violoncello reflects the weight of history, and then piano appears. Such expression means makes the whole music level clearer. Poem-chanting situation is shown in chorus. The melody of the third movement - The Yellow River in Wrath is painful and melodious. Chinese traditional national music instruments and expression forms are added in this section. For example, bamboo flute is used at the beginning; the piano is used to imitate the tone of Guzheng; music method of northern Shaanxi is used to describe the water from the Yellow River. These expression means with Chinese style show era depth of the works, and embody sadness of our motherland which was trampled on by invaders. The fourth movement - Defending Yellow River enters the climax again. After the brass-wind instrument, the most magnificent piano section pushes the whole works to the climax with resounding emotional melody and emblems that anti-Japanese war of Chinese nation walks to the final victory. The largest characteristic of this movement is that it continuously adopts variation so that the works will not be monotonous without change in continuous resounding mood. Meanwhile, it also shows the fighting scene of Chinese people.

In the whole works, the highest skills of piano are used to show its strong manifestation desire and musical instrument advantage. Immortal Yellow River spirit of Chinese nation is best sublimated in this works.

\section{Yellow River Piano Concerto - deep envoy communicating with world music}

Although Yellow River Piano Concerto was born after the establishment new China, historical era feeling it shows is invariable. When people hear this works, their emotion will agitate and return to that period spontaneously. Thus, no matter how time flies, Yellow River Piano Concerto has been stamped with deep era brand and cannot be effaced.

Diplomatic envoy in the Cultural Revolution period. In the Cultural Revolution period when literature and art resources were literature and art deficient, Yellow River as a successful piano concerto was well welcomed by the public. After it was performed in public in 1970, Yellow River became a communication envoy bearing social mission. After foreign performance communication many times, Yellow River was rated as a perfect works fusing policies and art by foreign scholars. So, as a "diplomatic envoy", strong political element and perfect ornamental nature reflected in Yellow River was soon accepted by the world.

As a dual communication envoy identity, although Yellow River performed during feting important guests in China owns many political elements, perfect artistry of Yellow River is really appreciated by people. In other words, artistry of Yellow River is the key to conquering the world. Its artistry far surpasses its politic nature. This is also the cause why it owns historical communication value. 


\section{Further music culture exchange in the new period}

After the period when political exchange was very frequent and sensitive during the establishment of new China, the communication of Yellow River in the world flourished. 1970s era was the darkest Cultural Revolution period in Chinese society. Thus, communication of Yellow River once stagnated. Till 1980s, Yellow River gradually returned to the stage and developed to oversea public performance from Chinese public performance. Meanwhile, it represented communication between Chinese and global music cultures further tended to art. In 1983, Yin Chengzong as the creator of piano concerto Yellow River played a solo in American Carnegie Music Hall. In the performance, Yin Chengzong perfectly displayed fusion and mutual connection of Chinese and western cultures in Yellow River. Although in the following years after its creation, unique charm of Yellow River has been known to all, it still aroused giant echo of whole American society after the performance. American media evaluated Yellow River was an epic works breaking the boundary of culture and language and narrowing the distance between Chinese and Western cultures and also a treasure for Chinese music circle.

After Yellow River enjoys good fame, its position in international music circle is not just improved. Meanwhile, its communication value also boots. After more than 40 years after its creation, it has been performed in public in over 50 countries in the world. Its sales volume had exceeded ten millions early. It became the most outstanding works with the widest communication range in music history of 20th century.

Nowadays, Yellow River has frequently appeared in different large-scale performances. Besides, after different performance styles of three generations of pianists, pianist charm is added to it. This expands its way for communication of its historical value.

\section{Historical value of Yellow River}

\section{Strong national sense of identity}

Yellow River piano concerto is a works with strong cohesive force. Its audience scope is very wide, not just including vast Chinese people, but also involving overseas Chinese. An old overseas Chinese once said, "I experienced the era of Yellow River Cantata. Whenever I hear this song, I will be filled with tears. When remembering the past, I will further miss my motherland.” This is another sincere feeling of Yellow River - missing motherland, except motivating Chinese people to take courage to actively fight against enemies and defending the homeland in that period. In other words, Yellow River can arouse national sense of identity of countless overseas Chinese, historical overseas Chinese and patriotic emotion. Its intangible cohesive force makes people further advance bravely and know the Advance Bravely as a Chinese.

Chinese-Canadian piano educator Zhu Yun also played Yellow River Piano Concerto. At the mentioning of this works, he said, "Yellow River owns western music style and traditional characteristics of Chinese music. When the melody of The East Is Red begins, such music emotion can make every Chinese shed silent tears. Whenever hearing Yellow River, you will experience infinite glory and sense of pride as a Chinese. This greatly deepens exchange between Chinese and western music as well as cultural exchange and makes more overseas Chinese feel the sound of motherland.” Indeed, sincere movement in Yellow River emits endless lofty spirit and soaring determination. The bullying, inferiority feeling and oppression of China in that period are reflected in this works. Thus, historical value of Yellow River piano concerto imposes very high social influence for both old and young audiences. It not merely pleasing people audio-visually, but also raps audiences' soul and reaches resonance with them. Nowadays, historical value of Yellow River piano concerto has become a certificate of national sense of identity of generations of Chinese.

\section{Typical era mark}

Yellow River piano concerto reflects Chinese spirit. In terms of music art, its communication also successfully localizes western orchestral music in Chinese symphony circle. It can be said that 
Yellow River and The Butterfly Lovers are jointly rated as milestone works of Chinese symphony. The birth of Yellow River piano concerto also brings new trial for deduction of Chinese piano works, i.e. the new creation form of "piano-revised melody". Such creation form is few in early piano music works. Three Variations on Plum Blossom, Birds Paying Homage to The Phoenix, Ambush on All Sides and Music at Sunset Time did not appear until the Cultural Revolution period. In most of them, traditional folk instruments are re-played on piano. They describe people's life and things. Differently, Yellow River owns strong historical era sense and large music theme combining chorus and symphony. Such grand and magnificent works is recomposed to piano concerto, which is the first time in China. Such fusion of the similarities of Chinese and western music cultures highlight peculiar national character and historical feeling of Yellow River. It is just such western music expression form which highlights Chinese traditional national music style that pushes Yellow River Piano Concerto to the world and makes all people in the world know shameful history, tenacious struggling and indomitable national spirit of Chinese people in 1930s. Such fusion of western music makes Yellow River emit infinite art charm and national charm.

\section{Conclusion}

With historical deposition, connotation of Yellow River Piano Concerto becomes richer. Its invariable creativity and shock power continuously conquer generations of audiences. The historical value it communicates has clear directivity and symbolic meaning and represents endless solidarity spirit and strength. As a beacon lightening the night of Chinese history and mirror reflecting historical reality, Yellow River Piano Concerto shows the sincere feeling in ruthless times. It is exchanged by whooping, blood and tears of Chinese people. It is precious treasure which can represent 20th century and music in China.

\section{References}

[1] Mou Yanli, Historical value communicated by piano concerto Yellow River. Hundred Schools in Arts, 2010 (6)

[2] Liu Huiming, Culture and art value of piano concerto Yellow River. Home Drama, 2012 (6)

[3] Li Ni, Preliminary study on piano concerto Yellow River. Fujian Normal University, 2004

[4] Ren Lijun, Analysis of art charm of piano concerto Yellow River. Journal of Suzhou Education Institute, 2013, 16 (6)

[5] Cai Haiqin, Exploration of musical form of piano concerto Yellow River. Journal of Hubei Normal University (Philosophy and Social Sciences), 2013 (6) 